\title{
Optimalisasi Pengelolaan Administrasi Dan Sistem Informasi Desa Poncosari Untuk Meningkatkan Efisiensi Pelayanan Kepada Masyarakat
}

\author{
Sugito $^{*}$, Muhammad Zahrul Anam ${ }^{2}$ \\ 1,2. Program Studi Hubungan Internasional, Fakultas Ilmu Sosial dan IImu Politik, Universitas Muhammadiyah Yogyakarta \\ Email:sugito@umy.ac.id \\ DOI: $10.18196 / \mathrm{ppm} .31 .148$
}

\begin{abstract}
Abstrak
Pengelolaan administrasi kependudukan dan Sistem Informasi Desa (SID) Poncosari belum dilakukan secara optimal. Hal ini dikarenakan kurangnya petugas website, minimnya keterampilan jurnalisme dan fotografi, serta kurangnya pengetahuan teknis dari aparat dusun dalam tertib adminitrasi. Pengabdian dilakukan dengan menggunakan metode penyuluhan, pelatihan, dan pendampingan yang melibatkan masyarakat secara aktif dan bekerja sama dengan KKN Mahasiswa UMY 74 dan 88 di Desa Poncosari. Kegiatan yang dilakukan adalah penyuluhan dan pelatihan administrasi kependudukan, pelatihan adminitrasi, dan penyusunan proposal kegiatan bagi karang taruna, serta pelatihan pendampingan jurnalistik warga dan fotografi. Pengabdian ini telah meningkatkan kemampuan jurnalistik, fotografi, dan tata kelola administrasi sehingga dapat mengotimalkan pengelolaan web desa dan SID Poncosari. Tindak lanjut dari pengabdian ini adalah pendampingan pengelolaan website desa dan pengembangan literasi media serta peningkatan pengelolaan potensi wisata di Desa Poncosari.
\end{abstract}

Kata Kunci: Sistem Informasi Desa, Jurnalistik Warga, Fotografi, Administrasi,

\section{Pendahuluan}

Sesuai dengan amanat Undang-Undang (UU) Republik Indonesia Nomor 25 Tahun Tahun 2009 tentang Pelayanan Publik, pemerintah pusat hingga desa harus memberikan pelayanan publik kepada masyarakat. Prinsip desentralisasi dalam tata pemerintahan Repulik Indonesia saat ini, telah menempatkan pemerintah desa menjadi salah satu lembaga publik yang memliki kewenangan dan kewajiban untuk menyelenggarakan pelayanan publik secar terbuka, efisien, dan efektif serta bertanggung jawab. Ada beberapa hal yang harus dipersiapkan oleh pemerintah desa dalam melaksanakan fungsi dan tanggung jawab terhadap pelayanan publik (Apriansyah, Maullidina, Purnomo, 2018) :

1. Menata dan menetapkan standar pelayanan.

2. Menyusun, menetapkan, dan pemberitahuan maklumat pelayanan.

3. Menempatkan pelaksana yang ahli.

4. Menyediakan sarana, prasarana, dan/atau memberikan fasilitas pelayanan publik yang mendukung pelaksanaan pelayanan yang baik dan memadai.

Posisi dan kewenangan pemerintah desa dalam layan publik telah diakui oleh negara dengan dikeluarkannya Undang-Undang Nomor 6 Tahun 2014 tentang desa. Guna meningkatkan kualitas pelayanan publik, desa diberikan amanah sekaligus hak untuk mengembangkan Sistem Informasi Pembangunan Desa dan Pembangunan Kawasan Perdesaan. Dalam Pasal 86 (1) desa berhak mendapatkan akses informasi melalui sistem informasi desa yang dikembangkan oleh Pemerintah Daerah Kabupaten/Kota. (2) Pemerintah dan Pemerintah Daerah wajib mengembangkan sistem informasi desa dan pembangunan Kawasan Pedesaan. (3) Sistem informasi desa sebagaimana dimaksud meliputi fasilitas perangkat keras dan perangkat lunak, jaringan, serta sumber daya manusia. Tujuan dari SID sebagaimana yang diharapkan oleh desa, antara lain adalah Ketersediaan data, peningkatan kualitas pelayanan publik, pengelolaan seluruh potensi desa, mendorong partisipasi, transparansi dan akuntabilita, serta memperkuat modal sosial. 
Pemerintah Kabupaten Bantul telah menyambut dengan baik penerapan SID di seluruh desa. SID telah dikembangkan di Bantul dan lebih khusus di Desa Poncosari, Kecamatan Srandakan sejak 2014. Meskipun demikian, tampilan website desa yang menjadi salah satu bagian dari SID di Desa Poncosari belum juga optimal dimanfaatkan. Berdasarkan pada sumber https://poncosari.bantulkab.go.id/index.php/first, web tersebut belum didukung oleh informasi tentang profil dusun-dusun yang ada di Poncosari.
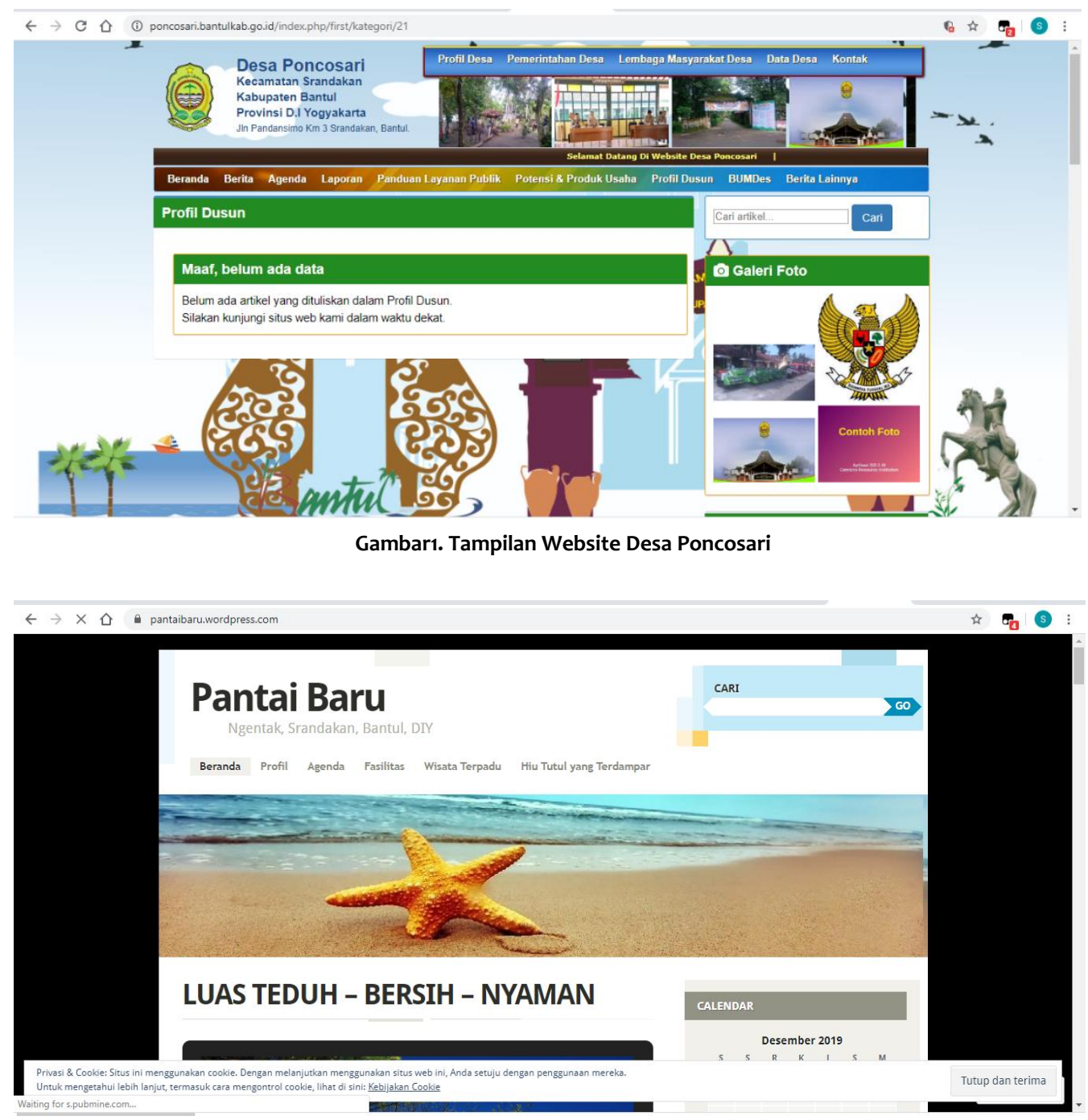

Gambar 2. Website Pantai Baru

Menurut kepala seksi pelayanan Desa Poncosari, kurang optimalnya web desa karena adanya keterbatasan pada sumber daya wartawan desa yang kurang mencukupi ${ }^{1}$. Keterangan ini diperkuat dengan pernyataan kepala Dusun Karang dan Ngentak yang mengeluhkan juga kurangnya kemampuan dan sumber daya yang mengelola informasi dan data di dusun masingmasing ${ }^{2}$. Padahal terdapat potensi dusun yang sebenarnya ingin diekspos oleh kedua dusun tersebut. Potensi dusun yang ada meliputi Pantai Baru yang telah dikembangkan menjadi tujuan

\footnotetext{
${ }^{1}$ Keterangan tersebut diperoleh dari diskusi dengan Kepala Seksi Pelayanan Desa Poncosari tanggal 19 Desember 2019.

${ }^{2}$ Keterangan tersebut diperoleh dari diskusi dengan Kepala Dusun Karang dan Ngentak tanggal 19 Desember 2019.
} 
wisata di Dusun Ngentak dan aktivitas ekonomi tradisional warga dalam pembuatan gula merah di Dusun Karang. Pengelolaan website Pantai Baru tidak optimal sehingga kurang diminati oleh calon wisatawan yang ingin mencari informasi lewat website maupun sosial media lainnya.

Sementara itu, profil Dusun Karang hanya tersaji di website Desa Poncosari yang sangat minim informasi.

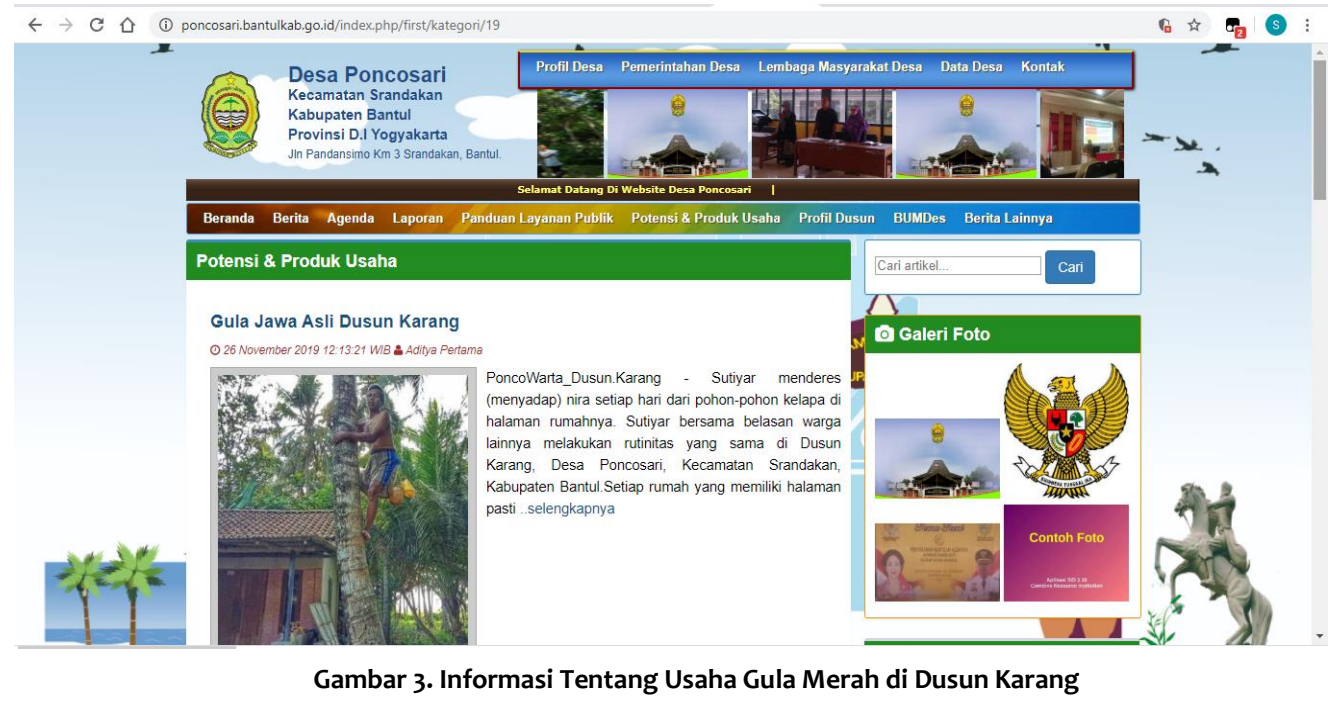

Sesuai dengan rencana pengembangan desa, kedua potensi tersebut akan dikembangkan jadi wisata terpadu. Selain potensi alam dan ekonomi, Dusun Ngentak telah memiliki Kelompok Sadar Wisata (Pokdarwis) dan karang taruna di kedua dusun tersebut. Namun demikian, potensipotensi tersebut belum dioptimalkan untuk mendukung pembangunan masyarakat.

Pengabdian masyarakat ini berujuan untuk meningkatkan pemahaman dan keterampilan perangkat Dusun Karang dan Ngentak dalam urusan tertib admistrasi dan pengarsipan dan meningkatkan kemampuan pemuda Dusun Karang dan Ngentak dalam membaut berita maupun konten website dan sosial media lainnya.

\section{Metode Pelaksanaan}

Metode pelaksanaan kegiatan ini bersifat pemberdayaan partisipatif. Pelaksana dari kegiatan ini adalah Dosen Pendamping lapangan beserta kelompok KKN Mahasiswa di Dusun Ngentak dan Karang, Desa Poncosari, Kecamatan Srandakan berkerjasama dengan Karang Taruna, Pokdarwis, dan perangkat dusun. Adapun tahapan pelaksanaan kegiatan adalah sebagai berikut :

\section{Persiapan Program}

a. TIM akan menyusun jadwal pelaksanaan program dengan berdiskusi bersama pihakpihak terkait agar sesuai dengan aktivitas masing-masing.

b. Tim akan mempersiapkan materi pelatihan bagi pardarwis, karang taruna, dan perangkat dusun untuk materi pengelolaan website, social media, teknik kewartawanan, dan tata adminstrasi.

c. Tim akan mempersiapkan alat dan sarana pendukung pelaksanaan program meliputi: alat tulis, tas, dan materi peltihan.

\section{Sosialisasi Program}

Tim akan mensosialisasikan kepada Perangkat Dusun, pokdarwis, dan karang 
taruna dalam forum rapat bersama. 3. Pelatihan Pengelolaan Website dan Social Media untuk Promosi Wisata Bagi
Pokdarwis dan Karang Taruna.

Pelatihan ini ditujukan untuk meningkatkan pengetahuan dan keterampilan pokdarwis Pantai Baru dan karang taruna Dusun Ngentak Karang dalam mengelola isi dan tampilan website untuk lebih menarik bagi pengunjung website sehingga meningkatkan angka kunjungan wisata ke Pantai Baru dan Dusun Karang. Pelatihan akan difasilitasi oleh narasumber yang berkompeten dalam dunia periklanan berbasis website dan social media UMY. Outputnya adalah website dan instagram Pantai Baru dan Desa Poncosari.

\section{Pelatihan Teknik Kewartawanan untuk Karang Taruna Ngentak dan Karang}

Pelatihan ini ditujukan untuk meningkatkan kemampuan pemuda dusun dalam melaksanakan peliputan dan pembuatan berita untuk dapat mengeksplorasi potensi dusun dan menyampaikannya ke masyawakat luas. Sebagai narasumber adalah wartawan Biro Humas dan Protokoler UMY. Outputnya adalah materi profile dusun dan berita tentang aktivitas dusun sebagai bahan untuk website Desa Poncosari.

\section{Pelatihan Tata Administrasi Dusun}

Pelatihan ini ditujukan untuk meningkatkan kemampuan operasionalisasi komputer dan tata kelola administrasi dusun yang lebih baik. Peserta pelatihan ini adalah perangkat Dusun Karang dan Ngentak dengan naras umber Tim KKN PPM.

\section{Evaluasi dan Monitoring}

Evaluasi dilakukan setiap minggu pada hari sabtu untuk melihat perkembangan pengelolaan website Pantai Baru dan Desa Poncosari serta ketertiban administrasi di Dusun Ngentak dan Karang. Montoring dilakukan dengan pengisisan log book atau catatan harian selama pelaksanaan pengabdian.

\section{Keberlanjutan}

Monitoring dan pendampingan juga tetap dilaksanakan minimal 1 bulan sejak berakhirnya masa pengabdian. Hal ini ditujukan untuk menjaga keberlanjutan website desa dan Pantai Baru. Monitoring ini dilakukan oleh Tim dan Tim KKN Mahasiswa beserta dengan pokdarwis dan karang tarun.

\section{Hasil dan Pembahasan}

Secara umum, program KKN PPM di Dusun Ngentak dan Karang, Desa Poncosari dapat berjalan sesuai dengan metode dan jadwal pelaksanaan kegiatan yang direncanakan. Pada awal pelaksanaan kegiatan, tim pelaksana melakukan kordinasi dengan Tim KKN Mahasiswa UMY kelompok 74 dan 88 yang berkegiatan di Dusun Ngentak dan Karang. Koordinasi menghasilkan sinkronisasi kegiatan antara program KKN PPM dengan KKN kelompok masingmasing yang bertujuan untuk mengoptimalkan pengelolaan administrasi desa dan SID di masing-masing dusun. Tim KKN PPM bersama dengan KKN 74 berkoordinasi dengan Pak Dukuh dan pengurus RT untuk melaksanakan program pelatihan adminitrasi kependudukan bagi pengurus dusun dan berkoordinasi dengan karangtaruna setempat untuk pelaksanaan pelatihan jurnalistik dan SID. Koordinasi dengan dukuh karang dan karang tarunanya dilakukan untuk koordinasi pelaksanaan pelatihan admistrasi karang taruna dan pelatihan jurnalistik dan SID. Tim juga berkordinasi dengan pihak desa untuk tempat pelaksanaan acara pelatihan.

Kegiatan-kegiatan yang berhasil dilaksanakan adalah sebagai berikut: 


\section{Pelatihan Tata Administrasi Dusum}

Pelatihan tentang adminitrasi dusun disesuaikan dengan kebutuhan masyarakat akan pelayanan administrasi kependudukan. Di Dusun Ngentak dan Karang didapati permasalahan warga pada tertib administrasi kependudukan. Selain itu pada bulan Maret 2020, Desa Poncosari akan mengikuti lomba Desa se-Kabupaten Bantul sehingga membutuhkan tertib administrasi desa khususnya data kependudukan. Berdasarkan pada permasalahan dan prioritas desa, maka kami mengadakan pelatihan untuk adminitrasi kependudukan.

Pelatihan dilaksanakan pada tanggal 21 Januari 2020 di Serambi Masjid Dusun Ngentak. Pelatihan yang bekerja sama Dinas Kependudukan dan Pencatatan Sipil Kabupaten Bantul inin dihadiri oleh 27 orang pengurus RT dan Dukuh Ngentak dan Karang. Paulus Eko Ananto, S.H., M.Sc, Kepala Seksi Identitas Penduduk Disdukcapil Kabupaten Bantul memberikan penjelasan teknis tentang proses mengurus dokumen kependudukan dan peran RT serta dukuh dalam tata laksana adminitrasi kependudukan. Program ini dinilai berhasil dari antusiasme RT untuk melakukan pendataan dokumen kependudukan warganya dan membantu proses penertiban yang dilakukan Dukcapil Kabupaten Bantul. Pelatihan ini berlanjut dengan sensus pendudukan yang dilakukan oleh KKN 74 dan 88 bekerja sama dengan pemuda karang taruna masing-masing dusun.

Sosialisasi dan pelatihan ini mampu meningkatkan kesadaran masyarakat tentang tertib kependudukan serta meningkatkan keterampilan para Kepala Dusun dalam melayani proses pendataan penduduk. Program penataan administrasi kependudukan kemudian dilanjutkan dengan pendataan penduduk untuk pemutakhiran data di website desa. Sensus penduduk dilakukan oleh para pemuda bekerja sama dengan KKN 74 dan 88.

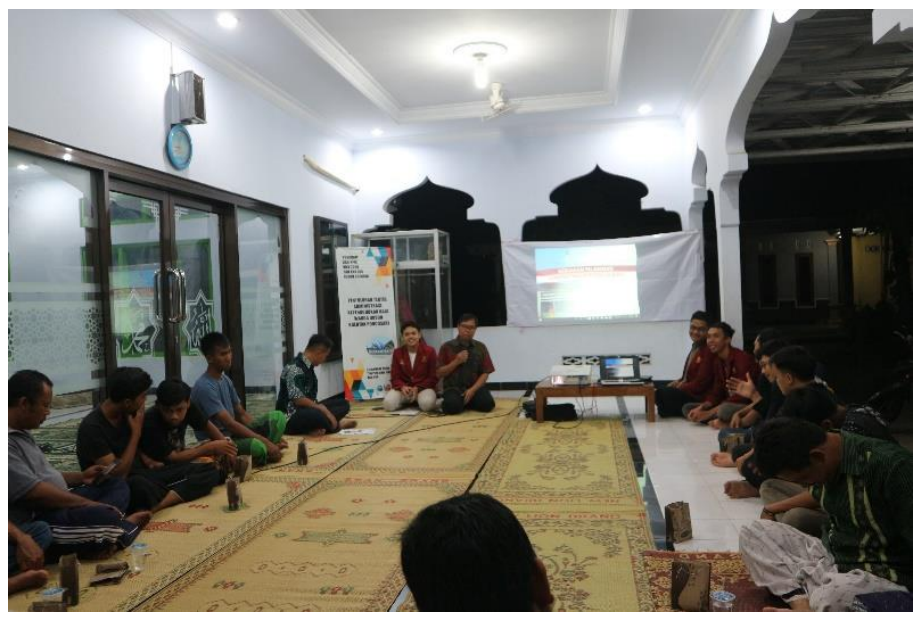

Gambar 4. Sosialisasi dan Pelatihan Adminitrasi Kependudukan

Selain pelatihan administrasi kependudukan, pelatihan administrasi dusun juga dilakukan dalam bentuk pelatihan bagi karang taruna dusun karang agar dapat membuat proposal kegiatan dan tertib sekretariat. Kegiatan yang dihasilkan dari diskusi tim dengan karang taruna dusun karang ini dilaksanakan pada tanggal 30 Januari 2020. Instruktur dalam pelatihan ini adalah Sugito, SIP, M.Si. dan Zain Maulana, M.A., Ph.D dari Prodi Hubungan Internasional UMY. Keduanya menyampaikan materi tentang Teknik Penyusunan Proposal Kegiatan dan Tata Kelola Sekretariat. Pelatihan penyusunan proposal kegiatan ini telah berhasil memberikan pemahaman dan peningkatan keterampilan para pengurus karang taruna dalam menyusun proposal kegiatan pemuda. 


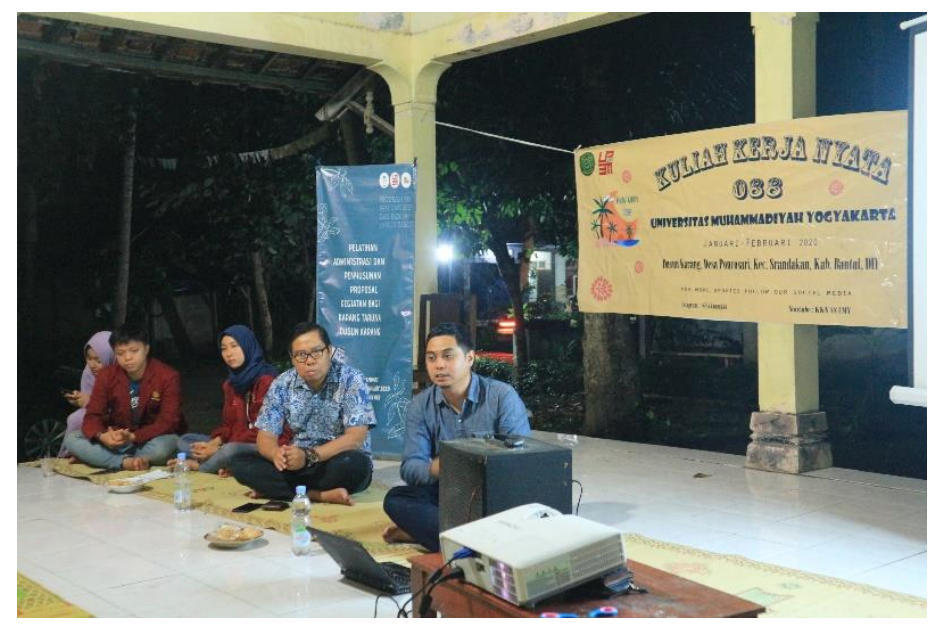

Gambar 5. Pelatihan Penyusunan Proposal Kegiatan

\section{Pelatihan Jurnalistik Warga dan Fotografi Dalam Rangka Optimalisasi Web Desa Poncosari}

Kegiatan ini sebenarnya dirancang untuk karang taruna dusun Ngentak dan Karang saja. Pada saat koordinasi dengan pihak Desa Poncosari, Tim menawarkannya untuk diperluas sasarannya kepada perwakilan pemuda tiap-tiap dusun. Usulan ini diterima baik oleh Bapak Agus Heri Kurniawan selaku Kepala Urusan Umum Desa dan mau bekerja sama untuk mengundang sekaligus menyediakan tempat Balai Desa untuk pertemuan. Pelatihan ini bertujuan untuk memberikan keterampilan jurnalistik dan fotografi kepada pemuda desa supaya mereka dapat menjadi wartawan desa yang akan mengisi web Desa Poncosari.

Kegiatan ini dilaksanakan pada tanggal 25 Januari 2020 dengan beberapa materi pelatihan yaitu arah pengembangan website dan SID Desa Poncosari, Teknik Dasar Jurnalisme Warga, Teknik Dasar Fotografi, dan diakhiri dengan praktik penulisan berita kegiatan pelatihan sebagai output kegiatan. Kegiatan ini disambut baik oleh peserta maupun pemerintah desa sehingga muncul kesepakatan untuk ditindaklanjuti dengan pembuatan komunitas wartawan Desa yang akan mendapatkan surat keputusan dari Kepala Desa. Pelatihan juga mampu memberikan pengetahuan dan keterampilan dasar tentang penulisan berita, pengambilan foto, serta pengelolaan sosial media untuk menghidupkan website desa.

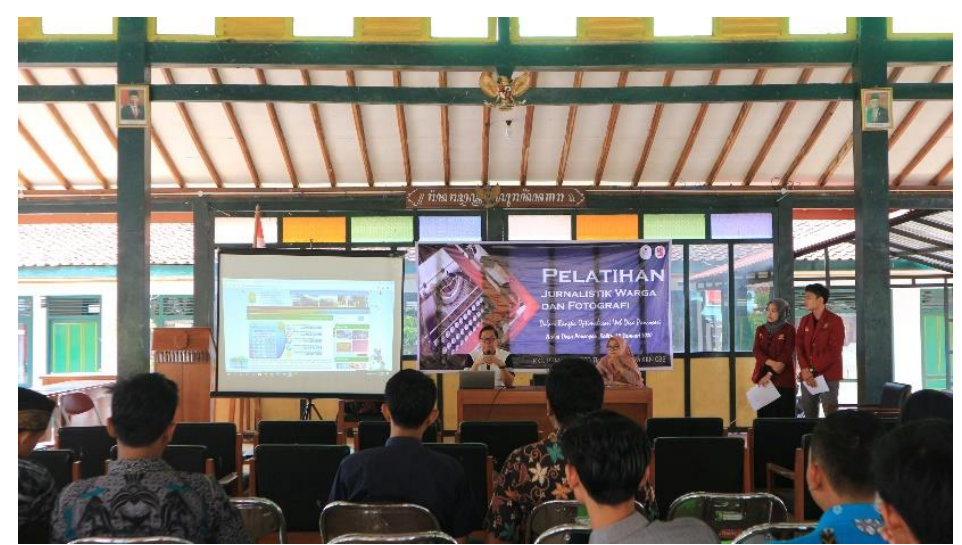

Gambar 6. Pelatihan Jurnalistik Warga dan Fotografi 


\section{Simpulan}

Pengabdian ini telah mampu meningkatkan kemampuan pengelola administrasi Dusun Ngentak dan Karang serta kemampuan para pemuda Desa Poncosari dalam jurnalisme, fotografi, dan pengelolaan website desa. Terbentuknya kelompok wartawan desa yang dikoordinasikan oleh Kepala Sie Pelayanan Umum Desa Poncosari juga menjadi output yang akan mampu menjaga keberlanjutan hasil-hasil pengabdian pascaakhir program. Keberadaan kelompok wartawan ini telah meningkatkan kinerja SID Poncosari sehingga semakin memudahkan masyarakat dalam mengakses informasi maupun layanan kependudukan.

Progam pengabdian selanjutnya di Desa Poncosari dapat dilakukan untuk memperkuat literasi media bagi pemuda maupun orang tua. Literasi media terutama di era kebebasan berpendapat di social media akan sangat penting untuk menjaga keutuhan masyarakat dan menfungsikan media social dengan lebih produktif. Perlu juga dilakukan perubahan fisik di Desa Poncosari terutama di wilayah pantai untuk lebih menarik minat pengunjung ke beberapa pantai yang ada di wilayahnya.

\section{Ucapan Terima Kasih}

1. Lembaga Penelitian, Publikasi dan Pengabdian Masyarakat (LP3M) Universitas Muhammadiyah Yogyakarta yang telah memberikan dana hibah pengabdian masyarakat.

2. Kepala Desa Poncosari dan Kepala Dusun Ngentak serta Karang bersama masyarakat yang telah berpartisipasi dalam kegiatan pengabdian masyarakat ini.

3. Kelompok KKN UMY 074 dan 088 Poncosari tahun 2020

\section{Daftar Pustaka}

Apriyansyah., Maullidinia, Isnaini., Purnomo, Eko Priyo. (200), "Efektivitas Sistem Informasi Desa (SID) Dalam Pelayanan Publik Di Desa Dlingo, Kecamatan Dlingo, Kabupaten Bantul", Jurnal Analisis Kebijakan dan Pelayanan Publik, Volume 4 No. 1, Juni 2018, pp. $10-24$

Undang-Undang Nomor 6 Tahun 2014 Tentang Desa

Undang-Undang Nomor 25 Tahun 2009 tentang Pelayanan Publik 